\title{
Maturação e qualidade de sementes de repolho de verão sob condições tropicais
}

\author{
Raquel Alves de Freitas; Warley Marcos Nascimento; Karuliny das Graças Coimbra
}

Embrapa Hortaliças, C. postal 218, 70359-970 Brasília-DF; raquel@cnph.embrapa.br; wmn@cnph.embrapa.br

\begin{abstract}
RESUMO
Avaliou-se o efeito do estádio de maturação dos frutos (síliquas) e da época de trilhagem sobre o potencial fisiológico de sementes de repolho, cultivar União. Em setembro de 2005 (200 dias após o transplantio), foi efetuada uma única colheita dos rácemos com síliquas em diferentes estádios de maturação, identificadas pelas colorações verde-escuro, verde-claro, arroxeada e bege. Estes estádios de maturação originaram sementes com coloração predominantemente verdes, castanho-claras, castanho-escuras e negras, respectivamente. Parte dos rácemos colhidos foi trilhada logo após a colheita e parte foi deixada em condições de laboratório, por uma semana, antes da trilhagem. $\mathrm{O}$ experimento foi conduzido no delineamento inteiramente casualizado, em esquema fatorial $4 \times 2$ (estádio de maturação das síliquas e época de trilhagem). As sementes foram submetidas a testes de grau de umidade, massa de 100 sementes, germinação, primeira contagem do teste de germinação, emergência de plântulas em casa de vegetação e envelhecimento acelerado. O potencial fisiológico das sementes variou entre os diferentes estádios de maturação das síliquas. Os resultados indicaram que os rácemos com síliquas de coloração verde-clara podem ser colhidos, desde que as sementes permaneçam no interior das síliquas por uma semana antes da trilhagem.
\end{abstract}

Palavras-chave: Brassica oleraceae var. capitata, colheita, qualidade de sementes.

\begin{abstract}
Maturation and seed quality of summer cabbage seeds under tropical conditions

The effect of maturation stages under tropical conditions, of summer cabbage cv. União fruits (seedpods), was studied on the seed physiological quality. On September, 2005 (200 days after transplanting), seedpods were harvested from racemes in the maturation (color) stages of intensive green, green, purple and beige, resulting in seeds with the predominant colors of green, brown, intensive brown and black, respectively. Part of the harvested racemes was threshed immediately after harvesting and part was stored at laboratory conditions for a week before being threshed. The experiment was conducted in a completely randomized design arranged in a factorial scheme $4 \times 2$ (seedpod maturation stages and threshing timing). Seeds were submitted to the tests of moisture content, mass of 100 seeds, germination, first counting, seedling emergence in greenhouse conditions and accelerated aging. Physiological seed quality varied among seedpod stages. The results indicated that the racemes with green seedpods may be harvested if the seeds remain for a week into seedpods before threshing.
\end{abstract}

Keywords: Brassica oleraceae var. capitata, harvesting, seed quality.

(Recebido para publicação em 14 de setembro de 2006; aceito em 19 de novembro de 2007)

$\mathrm{O}$ repolho (Brassica oleraceae var. apitata L.) pertence à família Brassicaceae é bienal em regiões de clima temperado. Em regiões tropicais encontram-se cultivares do tipo anual, denominadas cultivares de verão. Estas apresentam baixa exigência de frio para o florescimento. Apesar disso, quase a totalidade do repolho cultivado no Brasil é proveniente de sementes híbridas, importadas principalmente do Japão (Giordano, 2005). Em 2003, o mercado de sementes de repolho movimentou cerca de R\$ 9 milhões (ABCSEM, 2006). Portanto, tornam-se necessários estudos mais detalhados sobre o sistema de produção de sementes dessas cultivares; dentre eles, a determinação do ponto de maturidade e momento adequado para a colheita.

Nas brassicaceas, as inflorescências (rácemos) originam frutos denominados síliquas, que amadurecem na mesma sequiência de abertura das flores, de maneira que algumas síliquas sofrem deiscência antes que outras estejam completamente maduras. Assim, torna-se difícil a decisão quanto ao momento ideal para a colheita, visando assegurar máxima produtividade e qualidade das sementes (Gray et al., 1985; Maluf \& Corte, 1990).

As sementes atingem o máximo potencial fisiológico por ocasião da maturidade, sendo que, a partir desse ponto, inicia-se o processo de deterioração, caracterizado pela queda progressiva e irreversível da germinação e vigor (Delouche \& Baskin, 1973). Assim, para que um lote de sementes apresente o desempenho desejado é necessário que a colheita seja realizada o mais próximo possível da maturidade fisiológica.

Geralmente, a colheita de sementes de repolho é realizada à medida que as síliquas adquirem a coloração amarelopálido (Silva Júnior, 1987), e as sementes totalmente desenvolvidas apresentam cor creme clara (Pessoa et al., 1995) ou numa fase de transição entre as cores verde e marrom (Silva \& Silva, 1983). Já, Maluf \& Corte (1990) recomendam a colheita quando as sementes adquirem coloração marrom-escura ou negra. Deve-se evitar o atraso da colheita, pois pode ocorrer a deiscência das síliquas e perda irrecuperável de sementes. Torna-se, então, necessária a realização de colheitas parceladas, à medida que as síliquas vão atingindo o estádio ideal, uma vez que a maturação das síliquas ocorre de maneira desuniforme. Objetivou-se, nesse trabalho, avaliar o efeito do estádio de maturação das síliquas e da época de trilha das sementes sobre o potencial fisiológico de sementes de repolho da cultivar União. 


\section{MATERIAL E MÉTODOS}

O ensaio foi realizado em um campo de produção de sementes básicas de repolho (Brassica oleraceae var. capitata L.) cultivar União, na Embrapa Hortaliças, em Brasília, DF, em 2005. O campo de produção foi conduzido pelo método semente-semente. Os tratos culturais realizados seguiram as exigências para a cultura do repolho (Filgueira, 2003), sendo a irrigação efetuada por aspersão. $\mathrm{O}$ experimento foi conduzido no delineamento inteiramente casualizado, com quatro repetições e analisado num esquema fatorial 4 × 2 (quatro estádios de maturação e duas épocas de trilhagem.

Em setembro de 2005, cerca de 200 dias após o transplantio, fêz-se uma única colheita dos rácemos com síliquas nos quatro estádios de maturação (verdeescuro, verde-claro, arroxeada e bege). A colheita foi realizada aleatoriamente em vários locais do campo de produção, em quatro repetições. Foram colhidos 30 rácemos de cada coloração de síliquas. Logo após a colheita, foram retiradas amostras para determinação do conteúdo de água das sementes de cada coloração de síliquas. Para tanto, foi utilizado o método da estufa a $105 \pm 3^{\circ} \mathrm{C}$, durante 24 horas, conforme as Regras para Análise de Sementes (Brasil, 1992).

Quinze rácemos representando cada coloração de síliquas foram trilhados manualmente logo após a colheita e as sementes colocadas em peneiras de nylon para secar em condição ambiente. Os outros quinze rácemos restantes foram deixados nas mesmas condições por uma semana. Decorrido esse período, foram também trilhados manualmente. Foi realizada avaliação visual da coloração predominante das sementes recém-colhidas, mantendo-se a correspondência para cada estádio de maturação das síliquas.

As sementes secas e beneficiadas foram submetidas aos seguintes testes: 1) Massa de 100 sementes (efetuada com quatro repetições de 100 sementes, em balança analítica com precisão de três casas decimais); 2) Germinação (conduzido com quatro repetições de 50 sementes, distribuídas sobre duas folhas

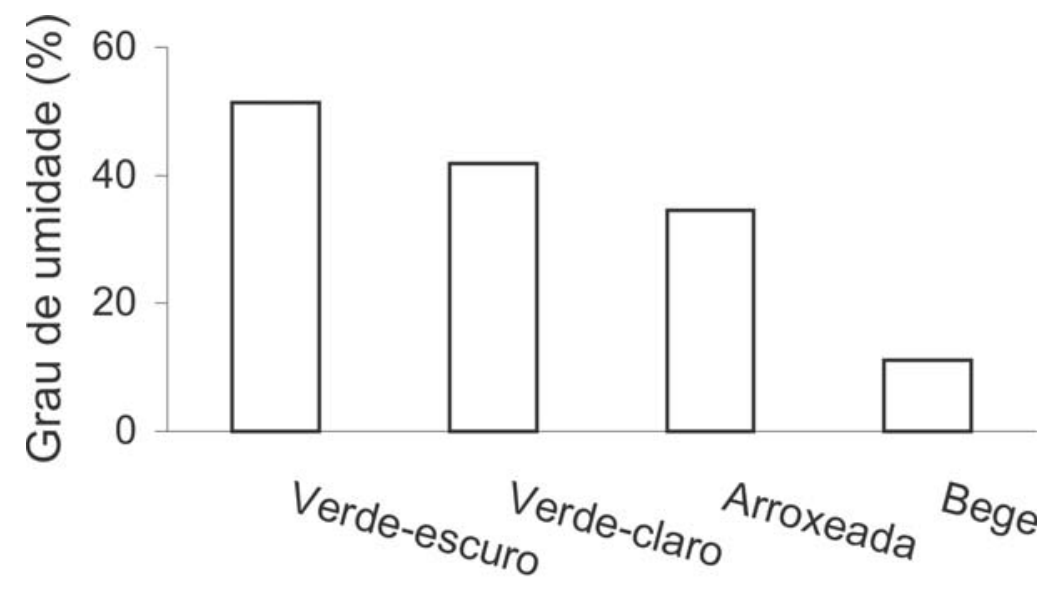

\section{Estádio de maturação das síliquas}

Figura 1. Valores médios do grau de umidade (\%) das sementes de repolho 'União' provenientes de síliquas colhidas em diferentes estádios de maturação. (Moisture content (\%) of 'União' cabbage seeds harvested at different seedpod maturation stages). Brasília, Embrapa Hortaliças, 2005.

de papel mata borrão, umedecidos com água, na proporção de 2,5 vezes a massa do papel seco e dispostas em caixas plásticas tipo "gerbox", mantidas em germinador com temperaturas alternadas de $20^{\circ} \mathrm{C}(16 \mathrm{~h})$ e $30^{\circ} \mathrm{C}(8 \mathrm{~h})$, em cada 24h; a avaliação das plântulas normais foi realizada aos cinco e dez dias após a instalação do teste, conforme Brasil, 1992); 3) Primeira contagem de germinação (registro do número de plântulas normais identificadas no quinto dia após a semeadura); 4) Envelhecimento acelerado (utilizou-se a metodologia proposta pela AOSA (1983) e descrita por Marcos Filho (1999); foram distribuídas 230 sementes sobre tela de alumínio fixada em caixa plástica tipo "gerbox", contendo $40 \mathrm{~mL}$ de solução saturada de $\mathrm{NaCl}$ (40 g de $\mathrm{NaCl} / 100 \mathrm{~mL}$ de água), conforme Jianhua \& McDonald (1996). As caixas contendo as sementes foram fechadas e mantidas a $41^{\circ} \mathrm{C}$, por 72 horas. Após esse período, as sementes foram submetidas ao teste de germinação. A avaliação da porcentagem de plântulas normais foi realizada aos cinco dias após a instalação do teste; Foi determinado, também, o grau de umidade das sementes após o período de envelhecimento, visando à avaliação da uniformidade das condições do teste); 5) Emergência das plântulas em casa de vegetação (foram utilizadas quatro repetições de 50 sementes, distribuídas em bandejas multicelulares de poliestireno expandido (isopor), contendo substrato comercial (Plantmax). As bandejas foram mantidas em casa de vegetação e irrigadas sempre que necessário. A contagem do número de plântulas emergidas foi realizada aos 15 dias após a semeadura).

Os dados não foram transformados por terem atendido às pressuposições dos testes de normalidade e de homogeneidade. Foram submetidos à análise de variância, efetuando-se os respectivos desdobramentos da interação (quatro estádios de maturação e duas épocas de trilhagem), quando necessários. A comparação entre o potencial fisiológico das sementes dos diferentes tratamentos foi efetuada pelo teste de Tukey, a 5\% de probabilidade.

\section{RESULTADOS E DISCUSSÃO}

Os frutos (síliquas) colhidos completamente imaturos, ou seja, com coloração verde-escuro, apresentaram sementes predominantemente verdes. Já as síliquas colhidas com coloração verdeclara, arroxeada e bege originaram sementes com predominância nas cores castanho-claro, castanho-escuro e negra, respectivamente. Jalink et al. (1998) constataram a existência de uma relação inversa entre a magnitude da fluorescência da clorofila e a qualidade das sementes de repolho. Esses autores 
Tabela 1. Valores médios obtidos nos testes de germinação, primeira contagem e emergência das plântulas em casa de vegetação de sementes de repolho 'União', de acordo com o estádio de maturação das síliquas e época de trilha das sementes. (Germination, first counting and seedling emergence of 'União' cabbage seeds from different seedpods maturation stages and threshing timing). Brasília, Embrapa Hortaliças, 2005.

\begin{tabular}{llccc}
\hline \multirow{2}{*}{$\begin{array}{l}\text { Estádio de } \\
\text { maturação das } \\
\text { síliquas }\end{array}$} & Época de trilha & $\begin{array}{c}\text { Germinação } \\
(\%)\end{array}$ & $\begin{array}{c}\text { Primeira } \\
\text { contagem (\%) }\end{array}$ & $\begin{array}{c}\text { Emergência } \\
\text { dastântulas } \\
(\%)\end{array}$ \\
\cline { 3 - 5 } Verde-escuro & Após a colheita & $87 \mathrm{~b}$ & $72 \mathrm{~b}$ & $69 \mathrm{~b}$ \\
& 7 dias após a colheita & $95 \mathrm{ab}$ & $88 \mathrm{ab}$ & $76 \mathrm{ab}$ \\
Verde-claro & Após a colheita & $88 \mathrm{~b}$ & $88 \mathrm{ab}$ & $78 \mathrm{ab}$ \\
& 7 dias após a colheita & $99 \mathrm{a}$ & $99 \mathrm{a}$ & $83 \mathrm{ab}$ \\
Arroxeada & Após a colheita & $94 \mathrm{ab}$ & $87 \mathrm{ab}$ & $82 \mathrm{ab}$ \\
& 7 dias após a colheita & $97 \mathrm{a}$ & $95 \mathrm{a}$ & $88 \mathrm{a}$ \\
Bege & Após a colheita & $99 \mathrm{a}$ & $95 \mathrm{a}$ & $92 \mathrm{a}$ \\
& 7 dias após a colheita & $100 \mathrm{a}$ & $99 \mathrm{a}$ & $93 \mathrm{a}$ \\
\hline CV (\%) & & 3,92 & 9,33 & 9,13 \\
\hline
\end{tabular}

Médias seguidas pela mesma letra na coluna não diferem entre si, teste de Tukey, $\mathrm{P}<0,05$. (Means followed by the same letter within a column are not significantly different at $\mathrm{P}<0.05$ according to Tukey's test).

Tabela 2. Massa de 100 sementes (g) e valores médios de plântulas normais (\%) obtidos no teste de envelhecimento acelerado em sementes de repolho 'União', de acordo com o estádio de maturação das síliquas e época de trilha das sementes. (Mass of 100 seeds $(\mathrm{g})$ and normal seedlings (\%) obtained after the accelerated aging test in 'União' cabbage seeds from different seedpod stages and threshing timing). Brasília, Embrapa Hortaliças, 2005.

\begin{tabular}{|c|c|c|c|c|c|}
\hline \multirow[b]{2}{*}{ Época de trilha } & \multicolumn{4}{|c|}{ Estádio de maturação das síliquas } & \multirow[b]{2}{*}{ Média } \\
\hline & $\begin{array}{l}\text { Verde- } \\
\text { escuro }\end{array}$ & $\begin{array}{l}\text { Verde- } \\
\text { claro }\end{array}$ & Arroxeada & Bege & \\
\hline \multicolumn{6}{|c|}{ Massa de 100 sementes $(\mathrm{g})$} \\
\hline Após a colheita & $0,351 \mathrm{Cb}$ & $0,483 \mathrm{Ba}$ & $0,541 \mathrm{Aa}$ & $0,485 \mathrm{Ba}$ & $0,460 a$ \\
\hline 7 dias após a colheita & $0,462 \mathrm{Aa}$ & $0,453 \mathrm{Aa}$ & $0,510 \mathrm{Aa}$ & $0,508 \mathrm{Aa}$ & 0,480 a \\
\hline Média & $0,407 \mathrm{~B}$ & $0,468 \mathrm{AB}$ & $0,497 \mathrm{~A}$ & $0,526 \mathrm{~A}$ & \\
\hline C. V. $(\%)$ & & & & & 3,81 \\
\hline \multicolumn{6}{|c|}{ Plântulas normais (\%) } \\
\hline Após a colheita & $38 \mathrm{Cb}$ & $80 \mathrm{Bb}$ & $92 \mathrm{Ab}$ & $92 \mathrm{Aba}$ & $76 \mathrm{~b}$ \\
\hline 7 dias após a colheita & $81 \mathrm{Ba}$ & $92 \mathrm{Aa}$ & $97 \mathrm{Aa}$ & $97 \mathrm{Aa}$ & $92 \mathrm{a}$ \\
\hline Média & $60 \mathrm{C}$ & $86 \mathrm{~B}$ & $95 \mathrm{~A}$ & $95 \mathrm{~A}$ & \\
\hline C. V. (\%) & & & & & 5,89 \\
\hline
\end{tabular}

Médias seguidas pela mesma letra maiúscula na linha e minúscula na coluna não diferem entre si, teste de Tukey, $\mathrm{P}<0,05$. (Means followed by the same uppercase letters within a row and lowercase letters within a column are not significantly different at $\mathrm{P}<0.05$ according to Tukey's test).

observaram um incremento de 90 a $97 \%$ na germinação quando foram descartadas $13 \%$ de sementes classificadas como de emissão de fluorescência muito alta. A fluorescência pela clorofila mostrouse um método adequado para a separação de sementes de repolho em função da qualidade fisiológica (Jalink et al., 1998). Resultados semelhantes foram obtidos por Perleberg et al. (2001) em sementes de cenoura.
O conteúdo de água mostrou-se elevado na colheita de síliquas de coloração verde-escura (Figura 1), observando-se um declínio lento até a colheita de síliquas arroxeadas, a partir do qual, ocorreu uma rápida desidratação das sementes (atingindo 11\% de água), acompanhada pela secagem das síliquas e escurecimento das sementes.

Pelos testes de germinação, primeira contagem e emergência das plântulas em casa de vegetação (Tabela 1 ), verificou-se que houve efeito da época de trilha das sementes provenientes de síliquas colhidas em fase menos adiantada de maturação. As sementes oriundas de síliquas verde-escuras, trilhadas imediatamente após a colheita apresentaram o pior desempenho. De modo geral, a qualidade das sementes de síliquas verde-claras trilhadas uma semana após a colheita mostrou-se semelhante à das sementes provenientes de síliquas arroxeadas e beges, independente da época de trilhagem das síliquas. A permanência das sementes no interior das síliquas, permite que a secagem ocorra de maneira mais lenta em relação às sementes que são extraídas imediatamente após a colheita dos rácemos. Em estudo com sementes de repolho, Gray et al. (1985) observaram que a secagem rápida das sementes promoveu decréscimo na qualidade. Além disso, é possível que haja uma continuação do processo de amadurecimento das sementes dentro dos frutos (síliquas). Esse assunto tem sido bastante estudado em sementes oriundas de frutos carnosos, como em abóbora (Araújo et al., 1982), melancia (Alvarenga et al., 1984), pepino (Barbedo et al., 1999) e melão (Lima \& Nascimento, 2003), dentre outros. Em quiabo, o armazenamento dos frutos antes da extração beneficiou a qualidade das sementes (Castro et al., 2004).

O estádio de maturação dos frutos influenciou a massa das sementes quando essas foram trilhadas imediatamente após a colheita (Tabela 2). Verificou-se um nítido acréscimo na massa das sementes até a colheita de síliquas com coloração arroxeada. A trilha das síliquas uma semana após a colheita beneficiou as sementes oriundas de vagens verde-escuras. $O$ acréscimo na massa de sementes foi suficiente para que estas atingissem massa semelhante àquela alcançada pelas sementes provenientes dos demais estádios de maturação dos frutos. Isso indica que há translocação de assimilados das síliquas para as sementes colhidas imaturas.

Acompanhando a mesma tendência dos testes discutidos anteriormente, pelo teste de envelhecimento acelerado, constatou-se que as sementes provenientes de síliquas verde-escuras foram as de me- 
nor vigor, quando comparadas às produzidas nas demais síliquas (Tabela 2). O armazenamento das síliquas antes da trilhagem permitiu acréscimo no vigor das sementes oriundas de síliquas verde-escura, verde-clara e arroxeadas. Observa-se que o acréscimo na qualidade das sementes de síliquas verde-clara foi suficiente para que estas atingissem nível semelhante ao das sementes provenientes de síliquas com coloração arroxeada e bege.

Os dados obtidos neste estudo permitem concluir que a colheita de sementes de repolho 'União' deve ser realizada quando as síliquas apresentam coloração verde-clara, desde que as sementes permaneçam por uma semana em condições ambientes no interior das síliquas antes da trilha. Esse procedimento reduz a possibilidade da ocorrência de perdas, tanto quantitativas quanto qualitativas. A permanência das sementes no campo deixaas expostas a condições climáticas desfavoráveis, o que pode causar danos fisiológicos, além da perda de sementes por deiscência dos frutos.

\section{REFERÊNCIAS}

ALVARENGA EM; SILVA RF; ARAÚJO EF; CARDOSO AA. 1984. Influência da idade e armazenamento pós-colheita dos frutos na qualidade de sementes de melancia. Horticultura Brasileira 2: 5-8.

AOSA - Association of official seed analysts. 1983. Seed vigor testing handbook. East Lansing: AOSA. 88p. (Contribution, 32).
ARAÚJO EF; MANTOVANI EC; SILVA RF 1982. Influência da idade e armazenamento dos frutos na qualidade de sementes de abóbora. Revista Brasileira de Sementes 4: 77-87.

ABCSEM. ASSOCIAÇÃO BRASILEIRA DO COMÉRCIO DE SEMENTES E MUDAS. 2006. Pesquisa de mercado. Disponível em: $<$ http://www.abcsem.com.br>. Acesso em: 24 fev. 2006.

BARBEDO CJ; BARBEDO ASC; NAKAGAWA J; SATO O. 1999. Efeito da idade e do repouso pós-colheita de frutos de pepino na semente armazenada. Pesquisa Agropecuária Brasileira 35: 839-847.

BRASIL. 1992. Ministério da Agricultura e Reforma Agrária. Regras para análise de sementes. Brasília: SNDA/DNDV/CLAV. 365p.

CASTRO MM; GODOY AR; CARDOSO AII. 2004. Qualidade de sementes de quiabo em função da idade e do armazenamento dos frutos. In: CONGRESSO BRASILEIRO DE OLERICULTURA, 44., 2004, Campo Grande. Horticultura Brasileira 22: 418, Suplemento 1 .

DELOUCHE JC; BASKIN CC. 1973. Accelerated aging techniques for predicting the relative storability of seed lots. Seed Science and Technology 1: 427-452.

FILGUEIRA FAR. 2003. Novo manual de olericultura: Agrotecnologia moderna na produção e comercialização de hortaliças. 3. ed. Viçosa: UFV. 412p.

GIORDANO LB. 2005. Produção de semente de repolho. In: CURSO SOBRE TECNOLOGIA DE PRODUÇÃO DE SEMENTES DE HORTALIÇAS, 5., 2005, Brasília. Palestras... Brasília: Embrapa Hortaliças, 2005 (CDROM).

GRAY D; HULBERT S; SENIOR KJ. 1985. The effects of seed position, harvest date and drying conditions on seed yield and subsequent performance of cabbage. Journal of Horticultural Science 60: 65-75.
JALINK H; FRANDAS A; VAN DER SCHOOR R; BINO JB. 1998. Chlorophyll fluorescence of the testa of Brassica oleracea seeds as an indicator of seed maturity and seed quality. Scientia Agricola 55: 88-93.

JIANHUA Z; McDONALD MB. 1996. The satured salt accelerated aging for small-seeded crops. Seed Science and Technology 25: 123131.

LIMA GP; NASCIMENTO WM. 2003. Influência da idade e armazenamento dos frutos na qualidade de sementes de melão cv. Eldorado 300. In: CONGRESSO BRASILEIRO DE OLERICULTURA, 43., 2003, Recife. Horticultura Brasileira, 21: 398, Suplemento 1.

MALUF WR; CORTE RD. 1990. Produção de sementes de repolho. In: CASTELLANE PD; NICOLOSI WM; HASEGAWA M. (eds). Produção de sementes de hortaliças. Jaboticabal: FCAV/FUNEP. p.177-192.

MARCOS FILHO J. 1999. Teste de envelhecimento acelerado. In: KRZYZANOWSKI FC; VIEIRA RD; FRANÇA NETO JB. (eds). Vigor de sementes: conceitos e testes. Londrina: ABRATES, cap.3. p.1-24.

PERLEBERG CS; CÍCERO SM; JALINK H; HEIJDEN G. 2001. Uso de fluorescência de clorofila para avaliar a qualidade fisiológica de sementes de cenoura. In: CONGRESSO BRASILEIRO DE SEMENTES, 12., 2001, Curitiba. Resumos... Brasília: Informativo ABRATES 11: 293.

PESSOA HBSV; NASCIMENTO WM; MELO PE; GIORDANO LB. 1995. Produção de sementes genéticas de repolho (Brassica olercea var. capitata) cv. União. Informativo ABRATES 5: 74-81.

SILVA JÚNIOR AA. 1987. Repolho: fitologia, fitotecnia, tecnologia alimentar e mercadologia. Florianópolis: EMPASC. 295p.

SILVA RF; SILVA JF. 1983. Produção de sementes de brássicas. Informe Agropecuário 9: $47-$ 49. 